\title{
Cerebral Vein and Sinus Thrombosis in Isfahan-Iran: A Changing Profile
}

\author{
Mohammad Saadatnia, Seyyed Ali Mousavi, Sassan Haghighi, \\ Ashraf Aminorroaya
}

\begin{abstract}
Objectives: This study was performed to investigate the clinical presentation and predisposing factors for cerebral vein and sinus thrombosis (CVST) in Isfahan, Iran. Methods: Data from the records of all patients with CVSTreferred to the largest tertiary-care hospital of Isfahan during a five-year period (1997 to 2001) were extracted and reviewed. Results: The number of cases with CVST diagnosed annually was 6, 9, 11, 14 and 15 patients, respectively. Thirteen men and 42 women were diagnosed to have CVST with the mean age of $35.1 \pm 3.8$ and $28.7 \pm 1.3$ years, respectively. Headache was the most frequent complaint (95\%) and $63 \%$ of patients had focal neurological symptoms, including seizure $(58 \%)$. Among possible predisposing factors, oral contraceptive pill was the most prevalent one, which was used by $38.1 \%$ of affected women for a period of as short as 1-3 months. Anticardiolipin antibodies were detected in $14 \%$ of patients. Conclusions: It seems that the annual incidence of CVST is increasing in Isfahan, perhaps due to more extensive intake of oral contraceptive pills and usage of more accurate modern diagnostic tools. The use of oral contraceptive pills was the most frequent predisposing factor; infections and postpartum factors were infrequently observed. Despite other reports from the Middle East, Behçet's disease is not a principal risk factor for CVST in Isfahani patients.
\end{abstract}

RÉSUMÉ: Thrombose cérébrale veineuse et sinusale à Isfahan, en Iran: un profil en voie de changement. Objectifs : Le but de cette étude était d'examiner le mode de présentation clinique et les facteurs prédisposants à la thrombose cérébrale veineuse et sinusale (TCVS) à Isfahan, en Iran. Méthodes : Nous avons révisé les dossiers de tous les patients atteints de TCVS référés au plus important hôpital de soins tertiaires d'Isfahan sur une période de cinq ans, soit de 1997 à 2001. Résultats : Le nombre de cas de TCVS diagnostiqués annuellement était de 6, 9, 11, 14 et 15 respectivement, soit 13 hommes et 42 femmes dont l'âge moyen était de 32,1 $\pm 4,3$ et 28,2 $\pm 3,4$ ans respectivement. La céphalée était le symptôme le plus fréquent, soit chez $95 \%$ des patients, et $63 \%$ avaient des symptômes neurologiques focaux dont des crises convulsives chez 58\%. L'utilisation de contraceptifs oraux était le facteur prédisposant potentiel le plus fréquent, soit chez $39 \%$ des femmes atteintes, même avec une utilisation qui pouvait être très courte (1 à 3 mois). Des anticorps anticardiolipine ont été détectés chez $14 \%$ des patients. Conclusions : L'incidence annuelle de TCVS semble à la hausse à Isfahan, possiblement en relation avec une utilisation plus répandue des contraceptifs oraux et d'outils diagnostiques modernes plus précis. La prise de contraceptifs oraux était le facteur prédisposant le plus fréquent et les infections et le post-partum étaient rares. Contrairement à des données publiées provenant du Moyen Orient, la maladie de Behçet n'est pas un facteur de risque majeur de la TCVS à Isfahan.

Can. J. Neurol. Sci. 2004; 31: 474-477

The wide spectrum of clinical presentations associated with cerebral vein and sinus thrombosis (CVST) makes it a diagnostic challenge. The etiology of CVST includes genetically determined procoagulant states, dehydration, Behçet's disease and septic thrombosis. ${ }^{1-10}$ While in the western countries hypercoagulable states are the most common etiology of CVST,, $11-12$ peripartum dehydration and septic thrombophlebitis of cranial venous sinuses have been reported as the most prominent predisposing factors of CVST in developing societies. ${ }^{4,7,13-14}$ Ethno-geographic differences also seem to influence the distribution of the etiologies. A recent study from
Saudi Arabia revealed Behçet's disease as the most prevalent cause of CVST. ${ }^{15}$

During recent decades, improvements in health care standards and application of modern techniques in Iran have led to earlier

From the Department of Neurology, Faculty of Medicine (MS, SAM); Endocrine \& Metabolism Research Center, (SH, AA), Isfahan University of Medical Sciences, Isfahan,, Iran

ReCeived DeCember 9, 2003. ACCePted InfinAlform June 21, 2004 Reprint requests to: Mohammad Saadatnia, Division of Neurology, Al-Zahra Hospital, Soffeh Street, Isfahan, Iran. E-mail: saadatnia@medscape.com 
diagnosis and treatment of infectious diseases and better maternal care during pregnancies. ${ }^{16,17}$ Oral contraceptive use has also increased during this period of time. ${ }^{18-20}$ With regard to these changes, we investigated the clinical presentation and predisposing factors of CVST in patients referred to the largest tertiary-care hospital (Al-Zahra hospital) in Isfahan, a centrally located city in Iran, over a five-year period from 1997 to 2001.

\section{Methods}

We reviewed the records of all patients with a hospital admission or discharge diagnosis of CVST from 1997 through 2001. Only those patients with a definitive diagnosis of CVST according to angiographic and/or magnetic resonance imaging MRI and magnetic resonance venography (MRV) - based on accepted definitions, ${ }^{21-27}$ were included in the study (for omission of pitfalls e.g. congenital variations in MRV, the presence of visible thrombus was confirmed by MRI and, if needed, follow-up MRI or MRI with contrast enhancement was performed). Patients' demographics, past medical history, current medication usage, physical and neurological complaints, onset of symptoms (acute: $<72 \mathrm{~h} /$ subacute: <1 month / chronic: progressive over months), family history and treatment options were entered into the database. In addition to routine blood chemistry, urine analysis, complete blood count and differential, erythrocyte sedimentation rate, prothrombin time, activated thromboplastin time, antinuclear antibody, evaluation for syphilis (VDRL), antineutrophil cytoplasmic antibody, anticardiolipin antibody and lupus anticoagulant were measured. To rule out Behçet's disease and other autoimmune disorders, rheumatological consultation was requested for all patients. If no obvious cause was found for CVST or a thrombotic event was present in his or her past or family history, antithrombin III, protein $\mathrm{C}$ and protein $\mathrm{S}$ were also measured as the assay became available (from 1999).

\section{RESUltS}

Fifty-five patients were identified with CVST(42 females, 13 males).The number of cases diagnosed annually (from 1997 to 2001) was $6,9,11,14,15$ patients, respectively. The mean of age for all patients was $29.5 \pm 1.3$ (17-71 years), it was 35.1 \pm 3.8 (2071 years) and $28.7 \pm 1.3$ (17-51) years for men and women, respectively $(\mathrm{P}=0.4)$. Table 1 shows the clinical features of patients during the acute phase (within two weeks of admission). Sudden onset of headache was present in $10.9 \% \quad(n=6)$ of patients. The onset of symptoms was acute in $29 \%(\mathrm{n}=16)$, subacute in $65 \%(\mathrm{n}=36)$ and progressive over months in $5 \%$ $(n=3)$ of patients.

The first two patients (diagnosed in 1997) had abnormal cerebral angiography whereas subsequent patients had diagnostic MRI and MRV.

Venous infarction occurred in 25 patients $(45 \%)$ including six subjects $(10.9 \%)$ with hemorrhagic infarction and five patients (9\%) with deep cerebral infarction. Partial or complete occlusion of the superior sagittal sinus was observed in $72 \%$ of cases $(n=40)$. It was associated with other sinus or venous occlusion in 12 subjects (lateral sinus in six, transverse sinus in two, deep cerebral vein in three patients and jugular vein in one patient) and was isolated in the remaining 28 patients. Isolated lateral
Table 1: Clinical features of CVST patients in Isfahan-Iran

\begin{tabular}{lr}
\hline Sign/Symptom & No. (\%) \\
Headache & $52(94.5 \%)$ \\
Papilledema & $40(72.7 \%)$ \\
Seizure & $32(58.1 \%)$ \\
Focal sensorimotor symptom & $25(45.4 \%)$ \\
Confusional state & $7(12.7 \%)$ \\
Stupor or coma & $6(10.9 \%)$ \\
Aphasia & $4(7.2 \%)$ \\
Vertigo & $4(7.2 \%)$ \\
Meningeal sign & $1(1.8 \%)$
\end{tabular}

Table 2: Predisposing factors of CVST in Isfahan-Iran

\begin{tabular}{|c|c|c|c|}
\hline Etiology & Males & Females & Total No. (\%) \\
\hline \multicolumn{4}{|l|}{ Hypercoagulable states } \\
\hline Oral Contraceptives & 0 & 27 & 27 (64\% of women) \\
\hline Postpartum & 0 & 4 & $4(9.5 \%$ of women $)$ \\
\hline Pregnancy & 0 & 3 & $3(7.1 \%$ of women $)$ \\
\hline Protein S Deficiency & 0 & 1 & $1(1.8 \%)$ \\
\hline Antiphospholipid Antibodies & s 2 & 6 & $8(14.5 \%)$ \\
\hline \multicolumn{4}{|l|}{ Autoimmune disorders } \\
\hline Lupus & 0 & 2 & $2(3.6 \%)$ \\
\hline Rheumatoid Arthritis & 0 & 1 & $1(1.8 \%)$ \\
\hline \multicolumn{4}{|l|}{ Other Connective Tissue } \\
\hline Diseases & 1 & 1 & $2(3.6 \%)$ \\
\hline \multicolumn{4}{|l|}{ Hematological Disorders } \\
\hline Polycytemia & 1 & 0 & $1(1.8 \%)$ \\
\hline Thrombocytosis & 1 & 0 & $1(1.8 \%)$ \\
\hline \multicolumn{4}{|l|}{ Others } \\
\hline Infection & 2 & 2 & $4(7.2 \%)$ \\
\hline Malignancy & 2 & 0 & $2(3.6 \%)$ \\
\hline Trauma & 2 & 0 & $2(3.6 \%)$ \\
\hline Inflammatory Bowel Disease & e 1 & 0 & $1(1.8 \%)$ \\
\hline Unknown & 7 & 4 & $11(20 \%)$ \\
\hline
\end{tabular}

sinus occlusion was reported in $9 \%(n=5)$ of patients.

The predisposing factors for CVST are shown in Table 2. The most frequent risk factor was the oral contraceptive pill (OCP), which was taken by $59.3 \%$ (16 out of 27 ) of female users for a period of as short as one to three months and for longer than three months in $40.7 \%$ of cases (11 out of 27 ).

High dose (norgestrel $0.5 \mathrm{mg}+$ ethinyl estradiol $0.05 \mathrm{mg}$ ) and low dose (norgestrel $0.3 \mathrm{mg}+$ ethinyl estradiol $0.03 \mathrm{mg}$ ) estrogen contraceptive pills were taken by four and 22 of the women in this series, respectively and one patient was using cyproterone compound (cyproterone acetate $2 \mathrm{mg}+$ ethinyl estradiol 0.05 $\mathrm{mg}$ ). 


\section{Discussion}

Our investigation shows an increase in the diagnosis of CVST annually. This is probably attributed to the increasing availability of modern noninvasive diagnostic techniques such as MRI and MRV in recent years and increased usage of OCPs for family planning in Iran. ${ }^{18-20}$

Symptoms and signs in this series were similar to other studies, ${ }^{1,2,11,12,15,28}$ but we observed a higher prevalence of sudden-onset headache $(10.9 \%)$ compared to previous reports. ${ }^{29}$

Although infection was considered as a main cause for CVST in previous studies, ${ }^{2,30}$ it has been found in only $8 \%$ of cases in recently performed series. ${ }^{11,12}$ Similarly, only $7 \%$ of our patients had an infectious cause for CVST. This is in accordance with the results of another study in the Middle East region, ${ }^{15}$ and may be the result of recent improvements of health and infectious care standards in Iran. ${ }^{16-17}$

No definitive case of Behçet's disease was detected in our patients, although other autoimmune disorders, (systemic lupus erythematosus, rheumatoid arthritis), were detected in $9 \%$ as predisposing factors. It has also been reported in $16 \%{ }^{2}$ and $25 \%{ }^{15}$ of CVST cases in similar studies. Our findings are in contrast to higher prevalence of this disorder in the Middle East region. ${ }^{31}$ In Arab patients in Israel, Kuwait and Saudi Arabia ${ }^{32-34}$ neuro-Behçet's was reported in $16 \%$ to $44 \%$ of patients but in Iran and Iraq ${ }^{35,36}$ less than $6 \%$ of patients with Behçet's disease had neurological manifestations. These regional differences may probably be due to ethnic as well as geographical factors.

In recent years, OCP intake, various types of coagulopathies and coexistence of these risk factors are frequently reported in patients with CVST. ${ }^{37-42}$ In our study, $64 \%$ of women had been on OCPs. Although the search for thrombophilia was not systematically and completely performed in the present study, a case of protein $\mathrm{S}$ deficiency was found among our most recently diagnosed patients. However, because of multidisciplinary management of CVST, it is necessary to perform a complete screening of various types of coagulopathies and thrombophilia even in patients with a definitive identified risk factor.

In the series reported by Bloemenkamp et $\mathrm{al}^{43}$ a considerable number of patients with deep vein thrombosis (DVT), who had a history of short-term OCPintake (less than one year), also had a prothrombotic defect. In the majority of our female patients who were taking OCP $(59.2 \%)$, the period of drug usage was short (one to three months), so it is possible that the presence of prothrombotic defects in this group of women is more likely. Although our results show that hypercoagulable states and autoimmune disorders were more prevalent risk factors in women as compared to men (in whom trauma and malignancy were more commonly detected), these data could not be supported by statistical analysis due to sample size limitations.

Elevated homocystein level, in recent studies after 2001, ${ }^{44-48}$ has been shown to be a common cause of CVST, and this also has not been investigated in this study.

In $20 \%$ of our patients, no definitive predisposing factor was found. However, even in other recent reports, ${ }^{11,12}$ no clear cause was observed in $20 \%$ to $30 \%$ of patients.

This study has its own special limitations including retrospective design, which might have led to bias. Another limitation of the present study is incomplete etiologic workup, which may be due to the retrospective design and unavailability of some diagnostic tests at the time of CVST diagnosis.

In conclusion, the incidence of CVST is increasing annually in Isfahan, Iran, perhaps due to availability of more accurate diagnostic techniques and greater OCP usage. Infections are not major causes of CVST, perhaps because of improved national health services. Unlike other studies in the Middle East region, Behçet's disease was not a frequent predisposing factor for CVST in Iran.

\section{REFERENCES}

1. Bousser MG, Barnett HJM. Cerebral Venous Thrombosis. Stroke: Pathophysiology, Diagnosis and Management, 2nd ed. New York: Churchill-Livingstone, 1992;517-537.

2. Bousser MG, Chiras J, Bories J, Castagne P. Cerebral venous thrombosis - a review of 38 cases. Stroke 1985; 16:199-213.

3. Gates PC. Cerebral venous thrombosis: a retrospective review. Aust NZ J Med 1986; 16:766-770.

4. Bansal BC, Gupta RR, Prakash C. Stroke during pregnancy and puerperium in young females below the age of 40 years as a result of cerebral venous sinus thrombosis. Jpn Heart J 1980;21:171183.

5. Buchanan DS, Brazinsky JH. Dural sinus and cerebral venous thrombosis: incidence in young women receiving oral contraceptives. Arch Neurol 1970;22:440-444.

6. Hickey WF, Garnick MB, Henderson JC, Dawson DM. Primary cerebral venous thrombosis in patients with cancer: a rarely diagnosed paraneoplastic syndrome. Am J Med 1982;73:740750 .

7. Southwick FS, Richardson EPJr, Swartz MN. Septic thrombosis of the dural venous sinuses. Medicine (Baltimore) 1986;65:82-106.

8. Gettelfinger DM, Kokmen E. Superior sagittal sinus thrombosis. Arch Neurol 1977;34:2-6.

9. de Bruijn SF, de Haan R J, Stam J. Clinical features and prognostic factors of cerebral venous sinus thrombosis in a prospective series of 59 patients J Neurol Neurosurg Psychiatry 2001;70:105108.

10. Bousser MG. Cerebral venous thrombosis: diagnosis and management. J Neurol 2000;247(4):252-258.

11. Ameri A, Bousser MG. Cerebral venous thrombosis. Neurol Clin 1992;10:87-111.

12. Villringer A, Mehraen S, Einhäupl KM. Pathophysiological aspects of cerebral sinus venous thrombosis. J Neuroradiol 1994;21:7280.

13. Srinavasan K. Ischemic cerebrovascular disease in the young: two common causes in India. Stroke 1984;15:733-735.

14. Cantu C, Barinagarrementeria F. Cerebral venous thrombosis associated with pregnancy and puerperium. Review of 67 cases. Stroke 1993;24(12):1880-1884.

15. Daif A, Awada A, Al-Rajeh S, et al. Cerebral venous thrombosis in adults: a study of 40 cases from Saudi Arabia. Stroke 1995;26:1193-1195.

16. The United Nation Team in Iran. United Nations Common Country Assessment for the Islamic Republic of Iran. 2003 Aug. Available from : URL: http://www.undp.org.ir/reports/CCAFINAL.pdf.

17. UNICEF. At a glance : Iran (Islamic Republic of). Available from : URL: http://www.unicef.org/infobycountry/iran.html.

18. Country Report on the Population Reproductive Health and Family Planning Program in the Islamic Republic of Iran. 1998: 1-6.

19. Roudi F. Iran's revolutionary approach to family planning. Popul Today 1999;27(7):4-5.

20. Aghajanian A, Mehryar AH. Fertility, contraceptive use and family planning program activity in Islamic Republic of Iran. Int Fam Plan Perspect 1999;25:68-77.

21. Dormont D, Anxionnat R, Evrard S, et al. MRI in cerebral venous thrombosis. J Neuroradiol 1994; 21: 81-99.

22. Macchi PJ, Grossman RI, Gomori JM. High field MRI of cerebral venous thrombosis. J Comput Assist Tomogr 1986; 10: 10-15. 
23. Lafitte F, Boukobza M, Guichard JP. MRI and MRA for diagnosis and follow-up of cerebral venous thrombosis (CVT). Clin Rad 1997; 52: 672-679.

24. Isensee C, Reul J, Thron A. Magnetic resonance imaging of thrombosed dural sinuses. Stroke 1994; 25: 29-34.

25. Bakac G, Wardlaw JM. Problems in the diagnosis of intracranial venous infarction. Neuroradiology 1997; 39: 566-570.

26. Dormont D, Sag K, Biondi A, Wechsler B, Marsault C. Gadoliniumenhanced MR of chronic dural sinus thrombosis. AJNR Am J Neuroradiol 1994; 16: 1347-1352.

27. Ayanzen RH, Bird CR, Keller PJ, et al. Cerebral MR venography: normal anatomy and potential diagnostic pitfalls. AJNR Am J Neuroradiol 2000; 21: 74-78.

28. Crawford SC, Digre KB, Palmer CA, Bell D, Osborn AG. Thrombosis of the deep venous drainage of the brain in adults. Analysis of 7 cases with review of the literature. Arch Neurol 1995;52:1101-1108.

29. de Bruijn SF, Stam J, Kapelle LJ. Thunderclap headache as first symptom of cerebral venous sinus thrombosis. CVST Study Group. Lancet 1996;348:1623-1625.

30. Shell CL, Rathe RJ. Superior sagittal sinus thrombosis still a killer. West J Med 1988;149:304-307.

31. James DG. Silk route disease. Postgrad Med J 1986;62:151-153.

32. Jaber L, Milo G, Halpern GJ, Krause I, Weinberger A. Prevalence of Behcet's disease in an Arab community in Israel. Ann Rheum Dis 2002;61:365-366.

33. Mousa AR, Marafie AA, Rifai KM, Dagani AI, Mukhtar MM. Behçet's disease in Kuwait. A report of 29 cases and a review. Scand J Rheumatol 1986;15:310-332.

34. Al Dalaan AN, Al Balaa SR, El Ramahi K, et al. Behçet's disease in Saudi Arabia. J Rheumatol 1994;21:658-661.

35. Ashjazadeh N, Borhani Haghighi A, Samangooie Sh, Moosavi H. Neuro-Behçet's disease: a masquerader of multiple sclerosis. A prospective study of neurologic manifestations of Behçet's disease in 96 Iranian patients. Exp Mol Pathol 2003;74(1):1722.

36. Alrawi ZS, Sharquie KE, Khalifa SJ, Alhadithi FM. Behçet's disease in Iraqi patients. Ann Rheum Dis 1986;45:987-990.

37. de Bruijn SF, Stam J, Koopman MM, Vandenbroucke JP. Casecontrol study of risk of cerebral sinus thrombosis in oral contraceptive users who are cautious of hereditary prothrombotic conditions. Br Med J 1998;316:589-592.

38. Martinelli I, Sacchi E, Landi G, et al. High risk of cerebral-vein thrombosis in carriers of a prothrombin-gene mutation and in users of oral contraceptives. N Engl J Med 1998;338:1793-1797.

39. de Bruijn SF, Stam J, Vandenbroucke JP, for the Cerebral Venous Sinus Thrombosis Study Group. Increased risk of cerebral venous sinus thrombosis with third-generation oral contraceptives. Lancet 1998:351:1404.

40. Martinelli I, Taioli E, Palli D, Mannucci PM. Risk of cerebral vein thrombosis and oral contraceptives. Lancet 1998;352:326.

41. Deschiens MA, Conard J, Horellou MH, et al. Coagulation studies, Factor V Leiden and anticardiolipin antibodies in 40 cases of cerebral venous thrombosis. Stroke 1996;27:1724-1730.

42. Kellett MW, Martin PJ, Enevoldson TP, Brammer C, Toh CM. Cerebral venous sinus thrombosis connected with 20210, a mutation of the prothanbil gene. J Neurol Neurosurg Psychiatry 1998:65:611-612.

43. Bloemenkamp KWM, Rosendaal FR, Helmerhorst FM, Vandenbroucke JP. Higher risk of venous thrombosis during early use of oral contraceptives in women with inherited clotting defects. Arch Intern Med 2000;160:49-52.

44. Rigamonti A, Carriero MR, Boncoraglio G, Leone M, Bussone G. Cerebral vein thrombosis and mild hyperhomocysteinemia: three new cases. Neurol Sci 2002;23(5):225-257.

45. Chaves C, Voetsch B, Loscalzo J, Caplan L, Chavali R. Extensive cerebral venous thrombosis associated with moderate hyperhomocyst(e)inemia and successfully treated with thrombolysis. Cerebrovasc Dis 2002;13(3):214-216.

46. den Heijer M. Hyperhomocysteinaemia as a risk factor for venous thrombosis: an update of the current evidence. Clin Chem Lab Med 2003;41(11):1404-1407.

47. Ventura P, Cobelli M, Marietta M, et al. Hyperhomocysteinemia and other newly recognized inherited coagulation disorders (factor $\mathrm{v}$ leiden and prothrombin gene mutation) in patients with idiopathic cerebral vein thrombosis. Cerebrovasc Dis 2004;17(2-3):153159. Epub 2003 Dec 23

48. Martinelli I, Battaglioli T, Pedotti P, Cattaneo M, Mannucci PM. Hyperhomocysteinemia in cerebral vein thrombosis. Blood 2003;102(4):1363-1366. Epub 2003 Apr 24 